\title{
Policy analysis indicates health-sensitive trade and subsidy reforms are needed in the UK to avoid adverse dietary health impacts post-Brexit
}

\author{
F. Freund $\mathbb{D}^{1,4} \bowtie$ and $M$. Springmann $\mathbb{1}^{2,3,4} \bowtie$
}

\begin{abstract}
The United Kingdom's food system will be greatly impacted by Brexit-related trade deals and policy developments-with implications for dietary risk factors and public health. Here we use an integrated economic-health modelling framework to analyse the impacts of different policy approaches to Brexit. A 'soft Brexit' that is in line with the EU-UK Trade and Cooperation Agreement increases diet-related mortality in the United Kingdom as costs for health-promoting and import-dependent foods increase and their consumption decreases. Negotiating free-trade agreements with the United States and Commonwealth countries as part of a 'global Britain' approach could triple the negative health impacts of Brexit as greater availability of energy-dense foods increases weight-related risks without meaningfully reducing dietary risks. Eliminating import tariffs on health-sensitive horticultural products could mitigate the negative health impacts of Brexit, and reforming agricultural subsidies to incentivize greater domestic horticultural production could lead to net health gains. Combining these health-sensitive approaches to trade policy and subsidy reform doubled the health gains, offering a promising approach for mitigating the detrimental impacts Brexit could have on dietary health in the United Kingdom.
\end{abstract}

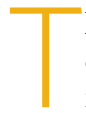
he United Kingdom's exit from the European Union (Brexit) on 31 January 2020 sparked intense discussions on the future relationship between the United Kingdom and the European Union on the one hand, and the United Kingdom and other potential trading partners on the other. A new free-trade agreement between the European Union and the United Kingdom, the EU-UK Trade and Cooperation Agreement, has been negotiated and took effect on 1 January 2021. However, many aspects are still uncertain, including questions of regulatory alignment and which form new domestic policies intended to replace former EU ones will take. In any case, withdrawing from EU institutions and regulations can be expected to lead to changes across all sectors of the British economy ${ }^{1,2}$ - with implications for public and private life in the United Kingdom and Europe.

In this article we focus on the impact that Brexit could have on the food supply in the United Kingdom ${ }^{3}$ and its implications for diets and diet-related health. Currently, about half of all food consumed in the United Kingdom (by value) is produced domestically, with 30\% imported from the European Union and 20\% imported from elsewhere 4 . The import dependence for some commodities can be considerably higher: for example, more than three-quarters of fruits and vegetables consumed in the United Kingdom are imported $^{4}$. Simultaneously, dietary risks, including low consumption of fruits and vegetables and high consumption of red and processed meat, are the second biggest risk factor for mortality in the United Kingdom, after tobacco ${ }^{5}$. Any changes in the trade and regulatory regime between the United Kingdom and the European Union (and its partners) will pose serious challenges to the British food system that will have consequences not only for agricultural trade and production, but also for dietary risks and diet-related health in the United Kingdom ${ }^{6,7}$.

We use a coupled economic-health modelling framework to provide a comprehensive analysis of Brexit-related policy approaches and their potential impacts on the food system and dietary health in the United Kingdom. Our point of departure is the EU-UK Trade and Cooperation Agreement agreed to on 24 December 2020 and provisionally applied since 1 January 2021 . The agreement includes free-trade provisions for all goods that comply with the appropriate rules of origin, as well as new regulations regarding customs procedures and product requirements, such as declarations, packaging and labelling. Trade with third countries that the European Union has free-trade agreements with, but which the United Kingdom has not yet been able to renegotiate, is governed by conditions set out by the World Trade Organization (WTO).

Policy responses to this kind of 'soft Brexit' range from international policies involving additional trade agreements and tariff reforms to domestic approaches involving national policy reforms. We constructed three policy scenarios, and combinations of these, to represent current policy initiatives and discussions.

First, we considered a 'global Britain' approach, in which the United Kingdom negotiates new trade agreements with the United States and Commonwealth countries. In this scenario, mutual tariffs between the trading partners are eliminated for all products.

Second, we considered a trade-focused 'food security' approach intended to address the high import dependence of fruits, vegetables and other horticultural products by safeguarding sufficient and affordable imports. In this scenario, tariffs on any horticultural imports, including fruits, vegetables, legumes and nuts, are eliminated unilaterally, irrespective of the country of origin.

Third, we considered domestic policy responses and focused on an intended reform of agricultural subsidies as part of a 'taking back control' approach. In line with a 'public money for public goods' intention, we constructed scenarios in which a portion of subsidies are directed towards the production of food commodities with beneficial health and environmental characteristics. Any

'Johann Heinrich von Thünen Institute-Federal Research Institute for Rural Areas, Forestry and Fisheries, Institute of Market Analysis, Braunschweig, Germany. ${ }^{2}$ Nuffield Department of Population Health, University of Oxford, Oxford, UK. ${ }^{3}$ Oxford Martin Programme on the Future of Food, University of Oxford, Oxford, UK. ${ }^{4}$ These authors contributed equally: F. Freund, M. Springmann. ${ }^{凶}$ e-mail: florian.freund@thuenen.de; marco.springmann@ndph.ox.ac.uk 
Table 1| UK statistics on food trade, self-sufficiency ratio and tariffs on imports from countries without mutual trade agreements

\begin{tabular}{|c|c|c|c|c|c|c|}
\hline \multirow[t]{2}{*}{ Food commodity } & \multicolumn{2}{|l|}{ Imports } & \multicolumn{2}{|l|}{ Exports } & \multirow{2}{*}{$\begin{array}{l}\text { Self-sufficiency } \\
\text { ratio }(\%)\end{array}$} & \multirow{2}{*}{$\begin{array}{l}\text { UK global } \\
\text { tariffs (\%) }\end{array}$} \\
\hline & Total (US\$ m) & Share EU (\%) & Total (US\$ m) & Share EU (\%) & & \\
\hline Wheat & 319 & 49 & 228 & 89 & 89 & 17 \\
\hline Other grains & 688 & 42 & 430 & 89 & 82 & 4 \\
\hline Vegetables, fruits, nuts & 9,539 & 56 & 783 & 78 & 24 & 11 \\
\hline Oil seeds & 532 & 36 & 76 & 95 & 72 & 0 \\
\hline Beef & 1,323 & 92 & 683 & 84 & 71 & 42 \\
\hline Sheep and goat meat & 418 & 19 & 588 & 91 & 108 & 47 \\
\hline Poultry & 3,803 & 83 & 618 & 73 & 75 & 17 \\
\hline Pork & 2,983 & 86 & 805 & 55 & 60 & 14 \\
\hline Vegetable oils and fats & 3,035 & 53 & 787 & 87 & 59 & 11 \\
\hline Dairy products & 4,064 & 99 & 2,403 & 76 & 86 & 33 \\
\hline Sugar & 800 & 60 & 261 & 67 & 69 & 31 \\
\hline
\end{tabular}

Non-tariff measures associated with customs procedures and product requirements apply to all food trade between the European Union and the United Kingdom. In line with previous analysis, we have assumed they amount to a tariff equivalent of $7.5 \%$ (Methods).

changes to agricultural subsidies that have until now been governed by the European Union's Common Agricultural Policy (CAP) could have major implications for the UK food system, which makes a stepwise introduction of new measures likely. In our main scenario, we therefore considered a redirection of a quarter of subsidies. Estimates for a repurposing of half and three-quarters are available in the Supplementary Information (Extended Data Figs. 4-6). We chose horticultural products, including fruits, vegetables, legumes and nuts, as eligible for such subsidies, in line with environmental and health assessments of foods ${ }^{8-10}$, and with an aim of mitigating the potential health impacts Brexit could have on health-promoting and trade-exposed food groups ${ }^{7}$ (Methods). Our scenario represents a stylized description of environmental and health-sensitive subsidy reform and not the UK Agricultural Bill in its current form.

The different Brexit-related policies and scenarios are not mutually exclusive. For example, a subsidy reform as part of a 'taking back control' approach can be pursued alongside new free-trade agreements with the United States and Commonwealth countries. However, in practice, each policy will have a different time horizon. We therefore first analyse each policy's impact on the food system and health in isolation, and then consider different policy combinations. The latter is meant to provide information on which policies are suitable for being part of a health-sensitive food-policy mix post Brexit.

We built a coupled economic-health modelling framework to analyse the different policy approaches to Brexit (Methods). In the economic analysis, we used a computable general equilibrium model with agricultural detail, the Modular Applied General Equilibrium Tool (MAGNET) ${ }^{11}$, to estimate the potential impacts that changes in trade costs could have on agricultural trade, production and consumption in the United Kingdom. The model combines economic theory and empirical data according to which relative prices of commodities adjust so that supply matches demand across different sectors and regions. Due to its structure, the model allows for the identification of causal effects of policy experiments and other external factors on parameters, such as economic output per sector, interregional trade and national consumption.

We paired the outputs of the economic analysis with a national risk-disease model to estimate the impacts that dietary changes related to Brexit could have on disease mortality in the United Kingdom. The risk-disease model is based on the concept of comparative risk assessment, used regularly by the Global Burden of Disease project, and relates changes in risk factors (such as reductions in fruit and vegetables) to changes in cause-specific mortality (such as cancer and coronary heart disease) $)^{12,13}$. Our UK-based model included eight diet- and weight-related risk factors and five disease end points, and it was parameterized with country- and age-specific data on mortality, population and body weight ${ }^{14,15}$. We used the model to estimate Brexit-related changes in the diet-related disease burden in the United Kingdom expressed as attributable deaths. Additional parameters, including deaths before age 70 and years of life lost, are included in the Supplementary Data File.

\section{Results}

The United Kingdom's food trade. The United Kingdom is highly dependent on food imports, most of which come from the European Union (Table 1). In 2019, the value of imports was especially high for horticultural products such as vegetables, fruits, roots and legumes (US\$9.5bn), followed by dairy (US $\$ 4.1 \mathrm{bn}$ ) and other animal products such as poultry (US $\$ 3.8 \mathrm{bn}$ ) and pork (US\$3.0 bn). The value of imports from the European Union constituted about half of the value of all imports for horticultural products, and above $80 \%$ for pork and poultry. The export values were generally smaller, with dairy having the greatest value (US\$2.4 bn), two-thirds of which went to the European Union. The self-sufficiency ratio, which indicates how much consumer demand is met by domestic production, was high for sheep and goat meat (108\%), part of which is produced for export, dairy products $(86 \%)$, and wheat and other grains (82-89\%). In contrast, self-sufficiency was low for horticultural products $(24 \%)$.

After Brexit, trade is governed by newly negotiated trade agreements with a set of trading partners (Supplementary Table 3), and the remaining trade by conditions set out by the WTO. Based on WTO conditions, the United Kingdom has issued global tariff lines that will apply to imports from countries with which it has no mutual trade agreement (Table 1 ). The tariffs are especially high for sheep and lamb meat (47\%), beef (42\%), dairy (33\%) and sugar (31\%), but still substantial for other commodities such as wheat (17\%), poultry (17\%), pork (14\%) and horticultural products $(11 \%)$. For trade between the United Kingdom and the European Union, tariffs continue to be set to zero, but new non-tariff measures associated with customs checks, product declarations and divergences of regulation and standards are expected to apply ${ }^{16}$.

The impacts of Brexit policies on food trade and production. In our analysis, the Brexit-related changes in trade costs associated with new non-tariff measures with the European Union, and the imposition of United Kingdom's global tariffs on trade with third 
a

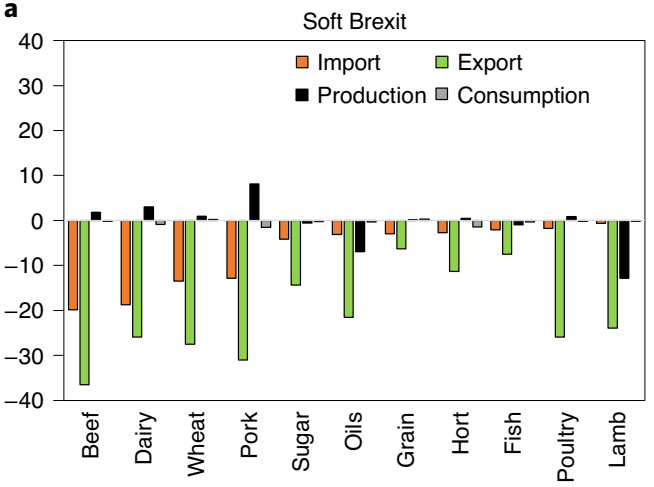

c

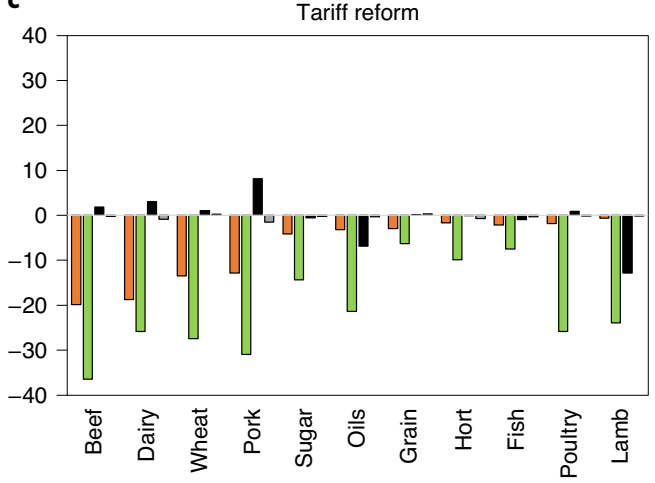

b

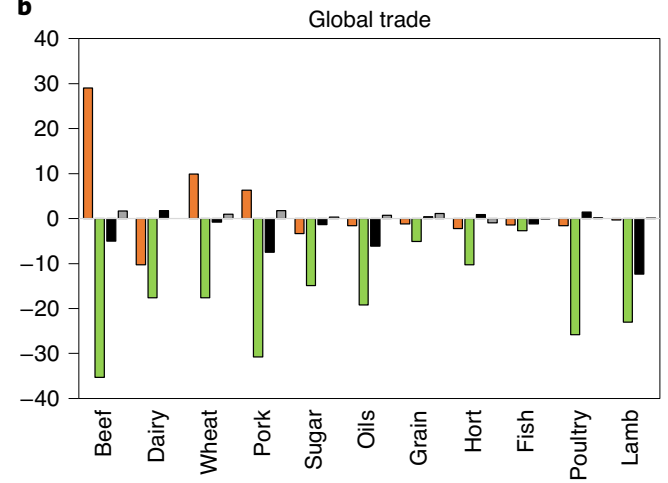

d

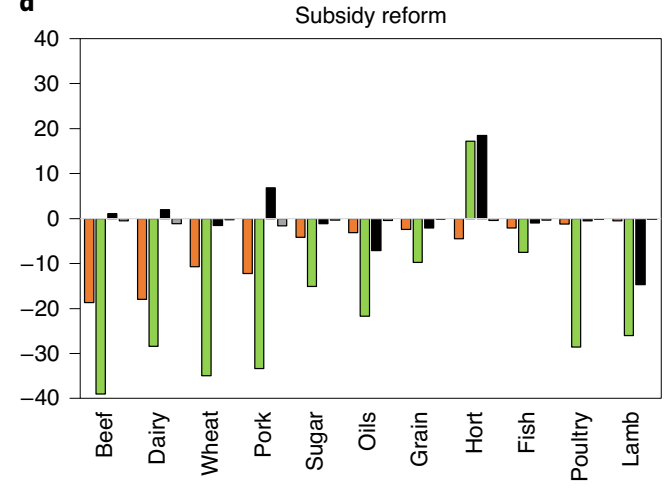

Fig. 1 | Percentage changes in agricultural imports, exports, production and consumption for various Brexit-related policies. a, Changes for a 'soft Brexit' in line with the EU-UK Trade and Cooperation Agreement. b-d, Changes for three related UK-based policies implemented in addition: a 'global Britain' approach in which free-trade agreements with the United States and Commonwealth countries are negotiated (b), a trade-focused 'food security' approach in which tariffs on horticultural imports from any country are eliminated (c), and a 'taking back control' approach in which agricultural subsidies are reformed such that a quarter are used to support horticultural production (d). Hort, horticultural products.

countries had a significant influence on agricultural trade and production (Fig. 1a). Imports declined for all agricultural commodities, with greatest reductions for beef $(-20 \%)$, dairy $(-19 \%)$, wheat $(-13 \%)$ and pork $(-13 \%)$. Concomitant reductions in exports and increases in domestic production mitigated some of those declines. Exports decreased by a quarter or more for beef $(-37 \%)$, pork $(-31 \%)$, wheat $(-28 \%)$, poultry $(-26 \%)$ and dairy $(-26 \%)$, whereas production increased for the same set of commodities, including by $8 \%$ for pork, $3 \%$ for dairy and $2 \%$ for beef. At the same time, production decreased for lamb $(-13 \%)$ and vegetable oils $(-7 \%)$.

The Brexit-related policies affected those changes in various ways. Negotiating global trade deals with the United States and Commonwealth countries as part of a 'global Britain' approach partially mitigated many of the Brexit-related reductions in imports and led to net increases in imports of beef (29\%), wheat (10\%) and pork $(6 \%)$ (Fig. 1b). Those increases were accompanied by reductions in domestic production, especially of pork $(-8 \%)$ and beef $(-5 \%)$. Eliminating import tariffs on horticultural products as part of a 'food security' approach led to a $40 \%$ less drastic reduction in horticultural imports, without affecting other commodities (Fig. 1c). A reform of agricultural subsidies as part of a 'taking back control' approach led to substantial increases in the production and export of horticultural products ( $18 \%$ each), with most of the additional production replacing the production of grains $(-2 \%)$ (Fig. $1 \mathrm{~d})$. Combining the different policies largely preserved each policy's specific trends (Extended Data Fig. 1).

The impacts of Brexit policies on food consumption. The changes in trade and production impacted incomes and the relative prices of foods that in turn influenced what is consumed by households (Fig. 2 and Extended Data Fig. 2). Under Brexit, the additional trade costs increased the price of foods, which in our analysis was associated with a reduction in total energy intake $\left(-81 \mathrm{kcalwk}^{-1}\right.$ per person), most of which was from dairy $\left(-21 \mathrm{kcal} \mathrm{wk}^{-1}\right.$, equivalent to $-40 \mathrm{~g} \mathrm{wk}^{-1}$ per person), red meat $\left(-17 \mathrm{kcal} \mathrm{wk}^{-1},-5 \mathrm{~g} \mathrm{wk}^{-1}\right)$, and fruits and vegetables $\left(-15 \mathrm{kcalwk}^{-1},-34 \mathrm{gwk}^{-1}\right)$. In contrast, eliminating mutual tariffs with new trading partners in the 'global Britain' scenario lowered trade costs, which was associated with a net increase in energy intake $\left(67 \mathrm{kcal} \mathrm{wk}^{-1}\right)$, mostly from foods whose imports increased, including grains $\left(42 \mathrm{kcal} \mathrm{wk}^{-1}, 15 \mathrm{~g} \mathrm{wk}^{-1}\right)$, vegetable oils $\left(21 \mathrm{kcalwk}^{-1}, 2 \mathrm{gwk}^{-1}\right)$ and red meat $\left(24 \mathrm{kcalwk}^{-1}\right.$, $\left.9 \mathrm{~g} \mathrm{wk}^{-1}\right)$. Policy combinations that included new global trade deals were associated with similar increases.

Tariff and subsidy reforms had less impact on the Brexit-related reductions in energy intake (Fig. 2). Eliminating tariffs on horticultural products mitigated some of the Brexit-related increases in trade costs, which was associated with a $50 \%$ less drastic reduction in fruit and vegetable intake and a quarter less severe reduction in energy intake. On the other hand, agricultural subsidy reform lowered commodity prices by increasing domestic production; this mitigated two-thirds of the reduction in fruit and vegetable intake, but did not affect the Brexit-related reduction in energy intake as grain intake decreased. Combining tariff and subsidy reforms completely mitigated the Brexit-related reduction in fruit and vegetable intake, but led to similar reductions in energy intake.

The impacts of Brexit policies on dietary health. Changes in food composition and total energy intake impact chronic-disease 


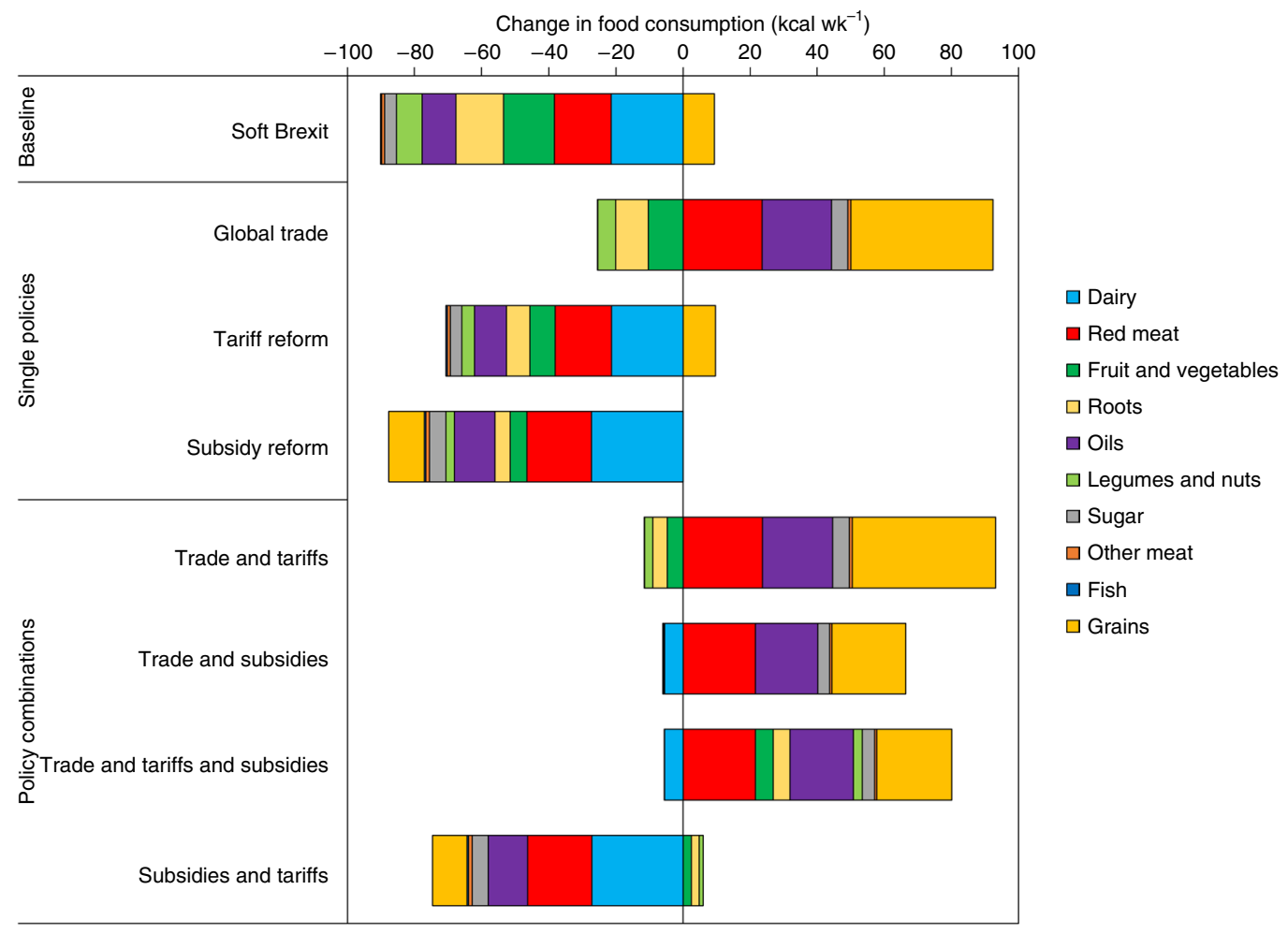

Fig. 2 | Change in food consumption per person ( $\mathbf{k c a l ~ w k}^{-1}$ ) by food group and Brexit-related policy. The policies include a 'soft Brexit' as baseline, as well as other policies implemented in addition, including new global trade agreements with the United States and Commonwealth countries, a tariff reform that eliminates import tariffs on horticultural products, an agricultural subsidy reform that incentivizes horticultural production, and combinations thereof.

incidence and mortality (Fig. 3). In our analysis, Brexit was associated with an increase in dietary risks, especially from lower fruit and vegetable consumption (associated with 420 and 520 additional deaths, respectively), and a reduction in weight-related risks, especially from reductions in obesity (associated with 650 fewer deaths). These changes resulted in a net increase in mortality ( 450 additional deaths; $95 \%$ confidence interval, 410-500), most of which were from coronary heart disease and cancers (Extended Data Fig. 3).

The Brexit-related policies affected diet- and weight-related risks in different ways (Fig. 3). New global trade agreements were associated with reductions in dietary risks from low fruit and vegetable intake, but also with increased risks from high red meat intake. In addition, the higher energy intake in that scenario was associated with increases in weight-related risks from greater levels of obesity. This reversal from weight-related gains to losses increased Brexit-related mortality impacts by a factor of three (1,500 additional deaths; 95\% confidence interval, 1,460-1,530). Combining new trade agreements with tariff and/or subsidy reforms affected dietary risks, but had little impact on weight-related risks and, as a result, was also associated with increased mortality (340-1,170 additional deaths across scenarios).

In contrast, the scenarios on tariff and subsidy reforms preserved the Brexit-related reductions in weight-related risks, while also reducing the Brexit-related increases in dietary risks, in particular from low fruit and vegetable intake (Fig. 3). Eliminating tariffs on horticultural products reduced dietary risks enough to compensate most of the overall mortality impacts associated with Brexit (to 22 additional deaths; 95\% confidence interval, 6-50). Reforming agricultural subsidies such that fruit and vegetable production is incentivized was associated with net health gains (400 fewer deaths; $95 \%$ confidence interval, 370-430) because dietary risks were reduced further. Combining both types of reforms led to net improvements in both diet- and weight-related risks and, as a result, was associated with the greatest reduction in mortality across the Brexit-related policy scenarios (810 fewer deaths; $95 \%$ confidence interval, 790-830).

\section{Discussion}

Brexit is expected to have significant impacts on the UK food system, which has implications for dietary risk factors and public health. The general chain of impacts leads from Brexit-related increases in trade costs to increases in prices and a decrease in income, which, all things being equal, results in reductions in consumption. Our analysis suggests that Brexit-related reductions in consumption could have two opposing effects. On the one hand, the reduced consumption of health-promoting foods, such as fruits and vegetables, is associated with increases in diet-related mortality. On the other hand, reduced energy intake is associated with reductions in mortality from obesity-related diseases. According to our analysis, the net population impact of a 'soft Brexit' as negotiated with the EU-UK Trade and Cooperation Agreement would be an increase in diet-related mortality of about 450 deaths (and double that for a 'hard Brexit' without such an agreement; Extended Data Figs. 4-6). Although this magnitude of impact might be considered low when compared to all diet-related deaths or the deaths due to COVID-19 (with more than 100,000 attributable deaths each in the United Kingdom), this finding nevertheless highlights that Brexit could have a detrimental impact for dietary and public health in the United Kingdom.

The Brexit-related policy approaches had different impacts on diet-related risk factors. Negotiating new global trade agreements with the United States and Commonwealth countries increased imports and consequently energy intake, but not of the health-promoting foods whose reductions are responsible for most of the increases in diet-related mortality. As a result, the 'global Britain' approach was associated with a greater increase in 


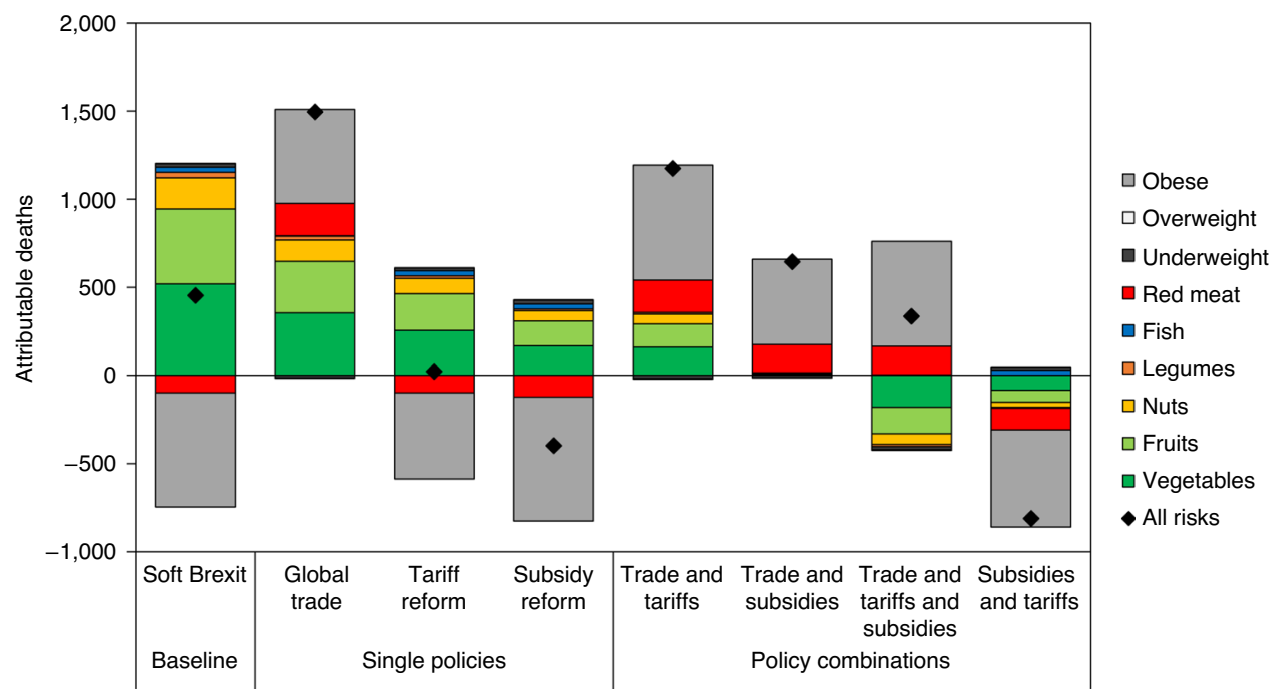

Fig. 3 | Number of attributable deaths by Brexit-related policy and risk factor. The policies include a 'soft Brexit' as baseline, as well as other policies implemented in addition, including new global trade agreements with the United States and Commonwealth countries, a tariff reform that eliminates import tariffs on horticultural products, an agricultural subsidy reform that incentivizes horticultural production, and combinations thereof. The risk factors include reduced intake of vegetables, fruits, nuts, legumes and fish, increased intake of red meat, and being underweight, overweight or obese at a population level.

diet-related mortality. In contrast, eliminating import tariffs on health-sensitive horticultural products as part of a trade-focused 'food security' approach compensated the negative health impacts of Brexit by reducing dietary risks without increasing weight-related risks. Reforming agricultural subsidies such that a portion of subsidies is coupled to producing foods with beneficial health and environmental benefits led to further reductions in dietary risks without increasing weight-related ones. These changes resulted in a net positive impact on mortality, and combining tariff and subsidy reforms maximized this impact.

Our analysis demonstrates how Brexit-related policies impact the UK food system and a comprehensive set of dietary risk factors. Our agriculture-economic analysis tracked the changes in trade, production and final consumption of food commodities, taking into account the supply-demand relationships across all economic sectors and countries. This level of detail is particularly important for analysing changes to the United Kingdom's global trade regime. The coupling of changes in both energy intake and dietary composition allowed us to analyse the health implications for a comprehensive set of risk factors. The scope of analysis advances the current level of understanding of Brexit-related health impacts because previous studies focused primarily on changes in fruit and vegetable consumption? ${ }^{7}$.

As any study, our analysis is subject to several caveats. The agricultural analysis took into account detailed land-use maps, but our analysis was undertaken at a national level. Estimating the impacts of Brexit-related policies at a more regional level and for specific income groups would increase the relevance for local decision-making and be an important avenue for future research. Similarly, estimating impacts with greater sectoral detail would increase the relevance for specific industries. Our analysis included 26 agricultural sectors, which can be considered detailed compared to similar assessment. However, this aggregation is coarse when compared to the almost 12,000 tariff lines that govern trade in specific commodities. More detailed impact assessments are therefore encouraged. Finally, the trade-related scenarios used values for non-tariff barriers that were estimated for trade between similar countries and regions, but not specifically between the European Union and the United Kingdom. Although these values are commonly applied to analyse the potential impacts of Brexit ${ }^{16,17}$, the analysis would benefit from being updated with sectorally detailed tariff-equivalent values estimated specifically for EU-UK trade once those become available.

Other caveats relate to the policies analysed-especially our stylized scenario on agricultural subsidy reform, which can be considered ambitious. Agricultural policy is a devolved issue in the United Kingdom, which complicates coordinated policy approaches. In addition, redirecting agricultural support to specific commodities, such as horticultural products, might be seen as trade-distorting measure by the WTO and therefore be contestable. However, the total value of agricultural support in the United Kingdom (around US $\$ 3.4 \mathrm{bn}^{18}$ ) is currently well below

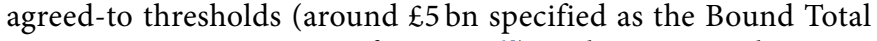
Aggregate Measurement of Support ${ }^{19}$ ) and is expected to stay fixed at this level until at least $2027^{20}$. Better political coordination across the devolved nations of the United Kingdom and more explicitly connecting the health and environmental characteristics of food groups to landscape-related indicators, such as ecosystem services, could further improve the applicability of the type of agricultural subsidy reform analysed here, but both approaches are to a large degree analogous when implemented consistently (Methods).

Our findings have clear policy implications for Brexit and other trade-related policies. The differentiated impacts that trade agreements could have on dietary composition and energy intake suggest that careful impact assessments are required to ensure trade agreements are in line with public health concerns. A too narrow focus on food prices and general food availability needs to be complemented by considering the potential changes in foods of public health importance, such as fruits and vegetables, and of weight-related risks. Trade agreements that only focus on food availability risk exacerbating the burden of overweight and obesity with detrimental impacts on public health. A two-way focus on food availability and dietary risks would benefit the design of domestic policies as exemplified by a health-sensitive reform of agricultural subsidies. Combining domestic and international policy approaches that are health-sensitive offers the best chances for improving public health while avoiding unintended consequences. 


\section{Methods}

Agriculture-economic model. We used an economic-health modelling framework to estimate the potential impacts that Brexit could have on agricultural trade, food consumption and diet-related health in the United Kingdom. The economic model consists of a computable general equilibrium (CGE) model of the global economy with a particular focus on agriculture in the European Union. CGE models combine economic theory and empirical data according to which relative prices of commodities adjust so that supply matches demand across different sectors and regions. CGE models represent the whole economy, and include the agriculture sector, as well as industrial and service sectors. Their focus is on real instead of financial variables; therefore, instead of changes in nominal exchange rates, they typically account for changes in real exchange rates, that is, the relative price of traded versus non-traded goods. Due to their structure, CGE models allow for the identification of causal effects of policy experiments and other external factors on parameters, such as economic output per sector, interregional trade and national consumption.

For this analysis, we used a CGE model with agricultural detail, MAGNET, to estimate the potential impacts that changes in trade costs could have on agricultural trade, production and consumption in the United Kingdom. One of the main features of MAGNET is the comprehensive representation of land resources as a factor of production, as well as its representation of agricultural policies such as the European Union's CAP and production quotas ${ }^{11}$. The price elasticities of food products that determine supply-demand reactions are in line with available meta-analyse ${ }^{21}$. Due to its specific focus, MAGNET is regularly employed to inform policy-makers and other stakeholders about the economic implications of various policies and other external factors related to agriculture ${ }^{22-24}$

In this version, MAGNET resolves 19 countries and regions, each with 34 sectors, including 26 agricultural ones (Supplementary Tables 1 and 2). Integrated into the model are projections of future socioeconomic development, which allows for the analysis of economic impacts and feedback effects of policies at a medium time scale. The development trajectory to 2030 uses baseline data on trade and economic output for the year 2014 from the Global Trade Analysis Project (GTAP) and then takes into account projections of a middle-of-the-road growth path of real gross domestic product ${ }^{25}$, including labour growth, and projections of biophysical yield developments of crops and pastures caused by climate and area changes. Free-trade agreements that have been agreed to (for example, between the European Union and Canada) are phased in gradually. Information on agricultural subsidies in the United Kingdom are based on GTAP data which reflect Organisation for Economic Co-operation and Development producer support estimates ${ }^{18}$. A detailed model description is provided in the Supplementary Information and by Woltjer et al. ${ }^{11}$. Brexit was not included in the baseline, and we instead specified it as individual scenarios to isolate its impacts.

We linked MAGNET to a dietary risk model to analyse the consequences of Brexit-related policies for public health in the United Kingdom. For that purpose, we used MAGNET's estimates of percentage changes in consumption, applied these to baseline consumption data and used these data in a comparative risk assessment of dietary and weight-related risk factors to estimate changes in mortality. We estimated baseline food consumption by adopting estimates of food availability from the Food and Agriculture Organization's food balance sheets, and adjusting these for the amount of food wasted at the point of consumption ${ }^{26,27}$ (see Supplementary Information for additional details on the consumption data).

Dietary risk model. We used a national risk-disease model to estimate the impact that dietary changes related to Brexit could have on disease mortality in the United Kingdom. The model is based on the concept of comparative risk assessment which relates changes in risk factors, such as reductions in fruit and vegetables, to changes in cause-specific mortality, such as cancer and coronary heart disease ${ }^{12}$. The same concept forms the basis of the Global Burden of Disease project, which tracks the impacts of different risk factors on mortality and morbidity in different regions and globally ${ }^{5}$.

The UK-based comparative risk assessment model included eight diet- and weight-related risk factors and five disease end points. The risk factors were high consumption of red meat, low consumption of fruits, vegetables, nuts, legumes and fish, and being underweight, overweight and obese, the latter of which are related to changes in energy intake from all foods. The disease end points were coronary heart disease, stroke, type 2 diabetes mellitus, cancer (in aggregate and as colon and rectum cancers) and respiratory disease.

We used publicly available data sources to parameterize the comparative risk analysis. We adopted relative risk estimates that relate change in risk factors to changes in disease mortality from meta-analysis of prospective cohort studies to minimize bias from individual studies ${ }^{9,28-34}$. Age-specific mortality and population data for the United Kingdom were adopted from the Global Burden of Disease project $^{14}$. Baseline data on the United Kingdom's weight distribution were adopted from a pooled analysis of population-based measurements undertaken by the NCD Risk Factor Collaboration ${ }^{35}$. We estimated changes in body weight based on the statistical relationship between calorie availability from all foods and body weight ${ }^{36}$

For our calculations, we assumed that the risk-disease relationships describe causal associations, an assumption supported by the existence of statistically significant dose-response relationships in meta-analyses, the existence of plausible biological pathways and supporting evidence from experiments, for example, on intermediate risk factors ${ }^{9,28-34,37,38}$. Based on evidence from trials and quasi-experiments, we also assumed that mortality rates adjust to changes in the associated risk factors within the same year ${ }^{39}$. For the uncertainty analysis, we used the low and high values of the $95 \%$ confidence intervals of the relative risk estimates. A detailed model description is provided in the Supplementary Information and by Springmann et al. ${ }^{40}$.

Brexit-related policy scenarios. We used the economic-health modelling framework to analyse Brexit and three related policy scenarios. The United Kingdom's default position is represented by a 'soft Brexit' scenario. In that scenario, a new trade agreement in line with the EU-UK Trade and Cooperation Agreement is implemented. No tariffs are applied between the United Kingdom and the European Union, but non-tariff measures that are associated with new trade and product regulation (for example, border checks and product requirements) are introduced. A 'hard Brexit' scenario that includes non-tariff measures and tariffs is included in a sensitivity analysis (Extended Data Figs. 4-6). In line with other analyses of Brexit ${ }^{16,17}$, we increased non-tariff measures between the European Union and the United Kingdom to a level that is lower than what would apply to countries without prior trade agreements and a history of regulatory alignment (Table 1). Imports from countries with which no new trade agreements have been negotiated are subject to their prior level of non-tariff measures in full, and to the United Kingdom's Global Tariffs, which are simplified and partly liberalized tariff lines based on the European Union's Most Favoured Nations tariffs. For the analysis, we mapped the detailed tariff lines to the commodities represented in the model by using the Tariff Analytical and Simulation Tool for Economists provided by the GTAP network ${ }^{41,42}$.

We constructed three scenarios that represent different ways the UK government could approach trade. First, for a 'global Britain' scenario, we assumed the United Kingdom focuses on negotiating new trade deals with the United States and Commonwealth countries. Mutual tariffs were reduced to zero in that scenario. Second, for a trade-focused 'food security' scenario, we assumed that tariffs on health-sensitive and import-dependent horticultural products (fruits, vegetables, legumes and nuts) are reduced to zero for imports from all countries.

Finally, for a 'taking back control' scenario, we focused on the domestic policy response of reforming agricultural subsidies. The UK government has announced its intention to reform agricultural spending, which within the European Union is regulated by the Common Agricultural Policy. In line with a 'public money for public goods' approach, the intention is that a portion of subsidies will be made conditional on the delivery of public benefits such as improvements in environmental sustainability and public health. In our policy scenario on agricultural subsidy reform, we represented this intention by coupling a quarter of subsidies to the production of food commodities with beneficial health and environmental characteristics (a portion we increased to half and three-quarters of subsidies in a sensitivity analysis; see Extended Data Figs. 4-6). In our model aggregation, we chose horticultural products (fruits, vegetables, legumes, nuts) for that purpose because these have beneficial health and environmental characteristics when compared to other foods represented in the model ${ }^{8,9}$, and increased production is required in pathways towards healthy and sustainable food systems $s^{10,43}$. This choice of food group is also in line with a focus on mitigating a Brexit-related reduction in fruit and vegetable consumption.

Approaches that focus on conditioning subsidies explicitly to the actual health and environmental characteristics of food commodities are, despite some differences, to a large degree analogous to our more sectoral food-group approach. For example, life-cycle analyses indicate that although production practices play a role in the environmental impacts of the food system, the impacts of what type of food is grown far outweighs how it is grown-a trend that is especially pronounced when comparing animal-source foods to plant-based ones, and when comparing different foods within the same region ${ }^{8,44}$. A similar trend has been identified for dietary risks and the associated health impacts: non-starchy plant-based foods such as fruits, vegetables, legumes and nuts have been clearly associated with reduced risks for various diet-related diseases, while other foods have either been associated with increased risk (red meat) or are seen as relatively risk neutral (poultry and dairy) compared with baseline diets ${ }^{9,10}$. Here we focus on these general health and environmental characteristics, not excluding that additional differentiation might sometimes be appropriate.

Reporting summary. Further information on research design is available in the Nature Research Reporting Summary linked to this article.

\section{Data availability}

The results data are available as a Supplementary Data File.

\section{Code availability}

The code used for the analysis is described in the Supplementary Information.

Received: 14 December 2020; Accepted: 18 May 2021;

Published online: 28 June 2021 


\section{References}

1. Chang, W. W. Brexit and its economic consequences. World Econ. 41, 2349-2373 (2018).

2. Sampson, T. Brexit: the economics of international disintegration. J. Econ. Perspect. 31, 163-184 (2017).

3. Lang, T. \& McKee, M. Brexit poses serious threats to the availability and affordability of food in the United Kingdom. J. Public Health 40, e608-e610 (2018).

4. Agriculture in the United Kingdom 2017 (DEFRA, 2018).

5. Forouzanfar, M. H. et al. Global, regional, and national comparative risk assessment of 79 behavioural, environmental and occupational, and metabolic risks or clusters of risks in 188 countries, 1990-2013: a systematic analysis for the Global Burden of Disease Study 2013. Lancet 386, 2287-2323 (2015).

6. Springmann, M. \& Freund, F. The Impacts of Brexit on Agricultural Trade, Food Consumption, and Diet-related Mortality in the UK. Oxford Martin School Working Paper (2018).

7. Seferidi, P. et al. Impacts of Brexit on fruit and vegetable intake and cardiovascular disease in England: a modelling study. BMJ Open 9, e026966 (2019).

8. Poore, J. \& Nemecek, T. Reducing food's environmental impacts through producers and consumers. Science 360, 987-992 (2018).

9. Bechthold, A. et al. Food groups and risk of coronary heart disease, stroke and heart failure: a systematic review and dose-response meta-analysis of prospective studies. Crit. Rev. Food Sci. Nutr. 59, 1071-1090 (2019).

10. Willett, W. et al. Food in the Anthropocene: the EAT-Lancet Commission on healthy diets from sustainable food systems. Lancet 393, 447-492 (2019).

11. Woltjer, G. B. et al. The MAGNET Model: Module Description (LEI Wageningen UR, 2014)

12. Murray, C. J. L., Ezzati, M., Lopez, A. D., Rodgers, A. \& Vander Hoorn, S Comparative quantification of health risks: conceptual framework and methodological issues. Popul. Health Metr. 1, 1 (2003).

13. GBD 2017 Diet Collaborators. Health effects of dietary risks in 195 countries, 1990-2017: a systematic analysis for the Global Burden of Disease Study 2017. The Lancet 393, 1958-1972 (2019).

14. GBD 2017 Causes of Death Collaborators. Global, regional, and national age-sex-specific mortality for 282 causes of death in 195 countries and territories, 1980-2017: a systematic analysis for the Global Burden of Disease Study 2017. Lancet 392, 1736-1788 (2018).

15. NCD Risk Factor Collaboration. Trends in adult body-mass index in 200 countries from 1975 to 2014: a pooled analysis of 1698 populationbased measurement studies with 19.2 million participants. Lancet 387, 1377-1396 (2016).

16. Dhingra, S. et al. The costs and benefits of leaving the EU: trade effects. Econ. Policy 32, 651-705 (2017).

17. Valverde, G. O. \& Latorre, M. C. A computable general equilibrium analysis of Brexit: barriers to trade and immigration restrictions. World Econ. 43, 705-728 (2020).

18. Agricultural Policy Monitoring and Evaluation 2018 (OECD, 2018).

19. UK Goods and Services Schedules at the WTO (UK Government, 2020); https://www.gov.uk/government/publications/uk-goods-and-servicesschedules-at-the-wto

20. The Path to Sustainable Farming: An Agricultural Transition Plan 2021 to 2024 (DEFRA, 2020); https://www.gov.uk/government/publications/agricultural transition-plan-2021-to-2024

21. Green, R. et al. The effect of rising food prices on food consumption: systematic review with meta-regression. Br. Med. J. 346, f3703 (2013).

22. Banse, M., van Meijl, H., Tabeau, A. \& Woltjer, G. Will EU biofuel policies affect global agricultural markets? Eur. Rev. Agric. Econ. 35, 117-141 (2008).

23. Boulanger, P. \& Philippidis, G. The EU budget battle: assessing the trade and welfare impacts of CAP budgetary reform. Food Policy 51, 119-130 (2015).

24. Helming, J. \& Tabeau, A. The economic, environmental and agricultural land use effects in the European Union of agricultural labour subsidies under the Common Agricultural Policy. Reg. Environ. Change 18, 763-773 (2018).

25. Riahi, K. et al. The Shared Socioeconomic Pathways and their energy, land use, and greenhouse gas emissions implications: an overview. Global Environ. Change 42, 153-168 (2017).

26. Gustavsson, J., Cederberg, C., Sonesson, U., Van Otterdijk, R. \& Meybeck, A. Global Food Losses and Food Waste: Extent, Causes and Prevention (FAO, 2011).

27. Food Balance Sheets: A Handbook (Food and Agriculture Organization, 2001).

28. Afshin, A., Micha, R., Khatibzadeh, S. \& Mozaffarian, D. Consumption of nuts and legumes and risk of incident ischemic heart disease, stroke, and diabetes: a systematic review and meta-analysis. Am. J. Clin. Nutr. 100, 278-288 (2014).

29. Aune, D. et al. Nut consumption and risk of cardiovascular disease, total cancer, all-cause and cause-specific mortality: a systematic review and dose-response meta-analysis of prospective studies. BMC Med. 14, 207 (2016).
30. Schwingshackl, L. et al. Food groups and risk of colorectal cancer. Int. J. Cancer 142, 1748-1758 (2018).

31. Schwingshackl, L. et al. Food groups and risk of type 2 diabetes mellitus: a systematic review and meta-analysis of prospective studies. Eur. J. Epidemiol. 32, 363-375 (2017).

32. Zheng, J. et al. Fish consumption and CHD mortality: an updated meta-analysis of seventeen cohort studies. Public Health Nutr. 15, 725-737 (2012).

33. Global BMI Mortality Collaboration. Body-mass index and all-cause mortality: individual-participant-data meta-analysis of 239 prospective studies in four continents. Lancet 388, 776-786 (2016).

34. Aune, D. et al. Fruit and vegetable intake and the risk of cardiovascular disease, total cancer and all-cause mortality-a systematic review and dose-response meta-analysis of prospective studies. Int. J. Epidemiol. 46, 1029-1056 (2017).

35. NCD Risk Factor Collaboration. Trends in adult body-mass index in 200 countries from 1975 to 2014: a pooled analysis of 1698 populationbased measurement studies with 19.2 million participants. Lancet $\mathbf{3 8 7}$, 1377-1396 (2016).

36. Springmann, M., Godfray, H. C. J., Rayner, M. \& Scarborough, P. Analysis and valuation of the health and climate change cobenefits of dietary change. Proc. Natl Acad. Sci. USA 113, 4146-4151 (2016).

37. Micha, R. et al. Etiologic effects and optimal intakes of foods and nutrients for risk of cardiovascular diseases and diabetes: systematic reviews and meta-analyses from the Nutrition and Chronic Diseases Expert Group (NutriCoDE). PLoS One 12, e0175149 (2017).

38. Schwingshackl, L., Hoffmann, G., Iqbal, K., Schwedhelm, C. \& Boeing, H. Food groups and intermediate disease markers: a systematic review and network meta-analysis of randomized trials. Am. J. Clin. Nutr. 108, 576-586 (2018).

39. Capewell, S. \& O'Flaherty, M. Rapid mortality falls after risk-factor changes in populations. Lancet 378, 752-753 (2011).

40. Springmann, M. et al. The healthiness and sustainability of national and global food based dietary guidelines: modelling study. BMJ 370, 2322 (2020).

41. Horridge, J. M. \& Laborde, D. TASTE: A Program to Adapt Detailed Trade and Tariff Data to GTAP-related Purposes (Centre for Global Trade Analysis, Purdue University, 2008).

42. Pelikan, J., Horrdige, M. \& Mustakinov, D. TASTE for GTAP 10: A Tariff Analytical and Simulation Tool for Economists. GTAP Resource \#6121 (Global Trade Analysis Project, 2020).

43. Springmann, M. et al. Health and nutritional aspects of sustainable diet strategies and their association with environmental impacts: a global modelling analysis with country-level detail. Lancet Planet. Health 2, e451-e461 (2018).

44. Clark, M. \& Tilman, D. Comparative analysis of environmental impacts of agricultural production systems, agricultural input efficiency, and food choice. Environ. Res. Lett. 12, 064016 (2017).

\section{Acknowledgements}

F.F. acknowledges an Oxford Martin Visiting Fellowship in support of the research. M.S. acknowledges support from the Wellcome Trust, Our Planet Our Health partnership on Livestock, Environment and People (LEAP), award number 205212/Z/16/Z.

\section{Author contributions}

F.F. and M.S. jointly designed the study, conducted the analysis and interpreted the results. F.F. compiled the economic model. M.S. compiled the health model. M.S. wrote the manuscript with inputs from F.F. F.F and M.S. reviewed and edited the manuscript.

\section{Competing interests}

The authors declare no competing interests.

\section{Additional information}

Extended data is available for this paper at https://doi.org/10.1038/s43016-021-00306-9.

Supplementary information The online version contains supplementary material available at https://doi.org/10.1038/s43016-021-00306-9.

Correspondence and requests for materials should be addressed to F.F. or M.S

Peer review information Nature Food thanks Helen Harwatt, Carmen Hubbard and Alan Matthews for their contribution to the peer review of this work.

Reprints and permissions information is available at www.nature.com/reprints.

Publisher's note Springer Nature remains neutral with regard to jurisdictional claims in published maps and institutional affiliations.

(c) The Author(s), under exclusive licence to Springer Nature Limited 2021 

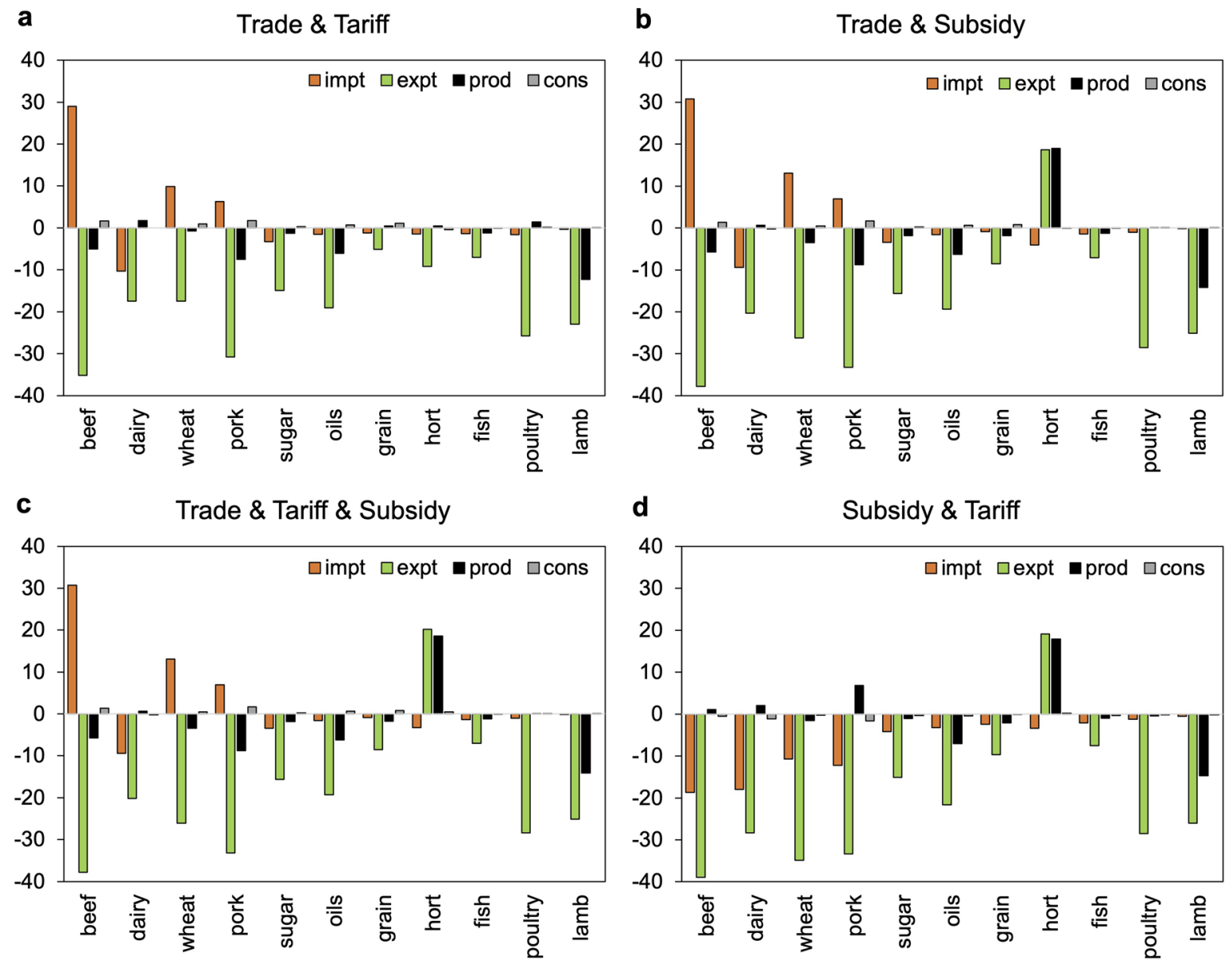

Extended Data Fig. 1 | Food-system changes for combinations of Brexit approaches. Percentage changes in agricultural imports (impt), exports (expt), production (prod), and consumption (cons) for different combinations of Brexit approaches, including new trade agreements and agricultural tariff reform (a), new trade agreements and agricultural subsidy reform (b), new trade agreements and agricultural tariff and subsidy reforms (c), and agricultural subsidy and tariff reforms (d). 


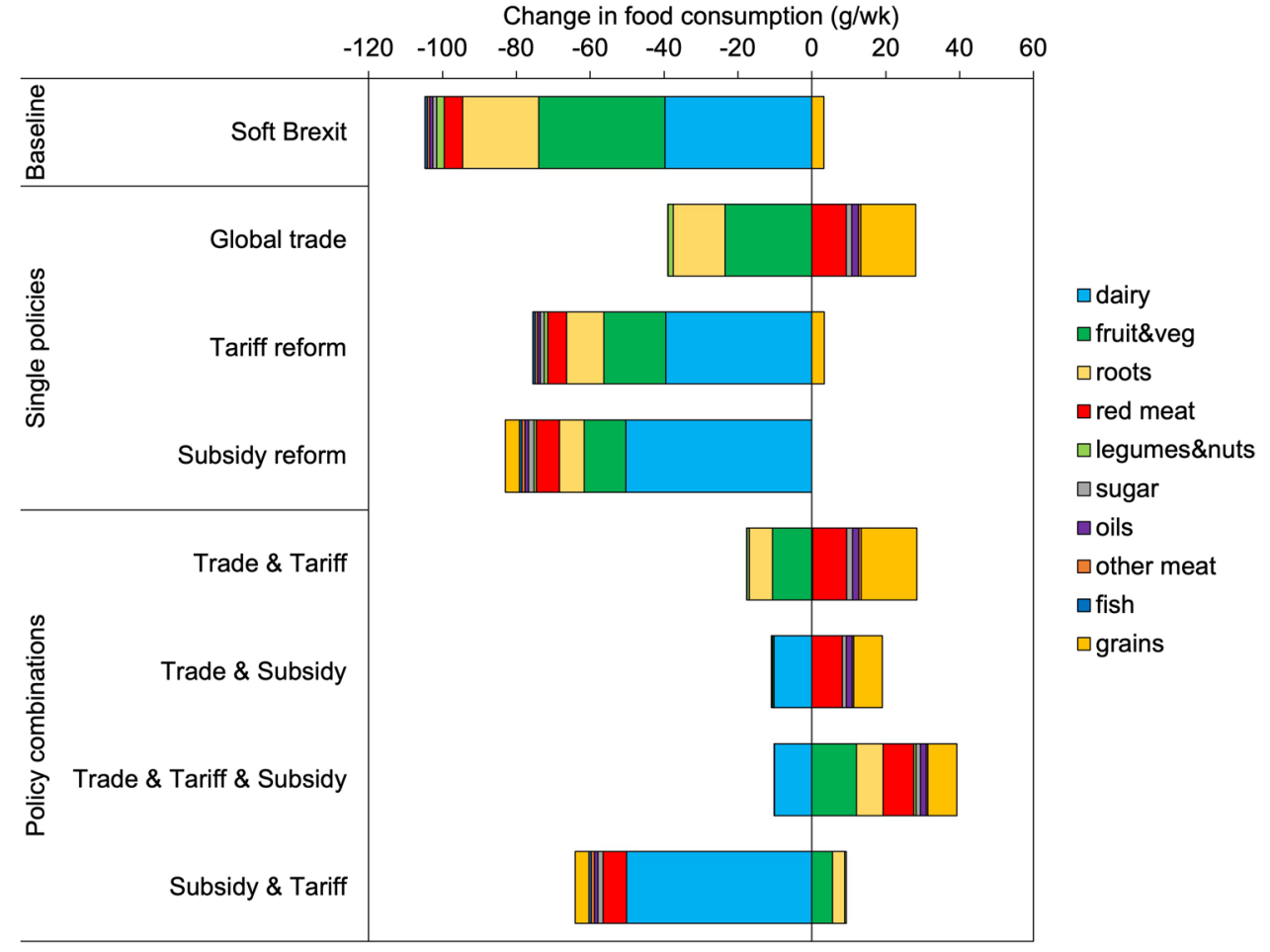

Extended Data Fig. 2 | Change in food consumption per person ( $\mathrm{g} / \mathrm{wk})$ by food group and Brexit-related policy. The policies include a 'Soft Brexit' as baseline, as well as other policies implemented in addition, including new global trade agreements with the USA and Commonwealth countries, a tariff reform that eliminates import tariffs on horticultural products, an agricultural subsidy reform that incentivises horticultural production, and combinations thereof. 


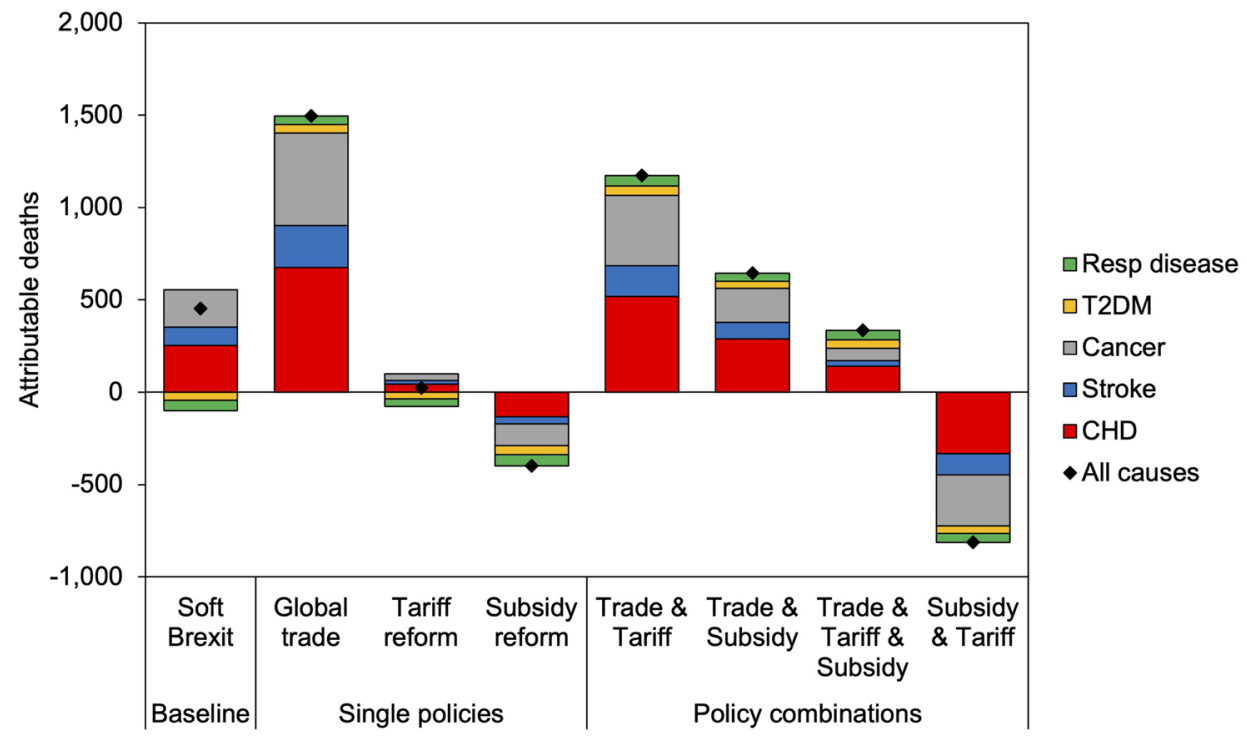

Extended Data Fig. 3 | Number of attributable deaths by Brexit policy and cause of deaths. The policies include a 'Soft Brexit' as baseline, as well as other policies implemented in addition, including new global trade agreements with the USA and Commonwealth countries, a tariff reform that eliminates import tariffs on horticultural products, an agricultural subsidy reform that incentivises horticultural production, and combinations thereof. The causes of deaths include coronary heart disease (CHD), stroke, cancer, type-2 diabetes mellitus (T2DM), respiratory disease (Resp disease), as well as their sum (All causes). 
a

Soft Brexit

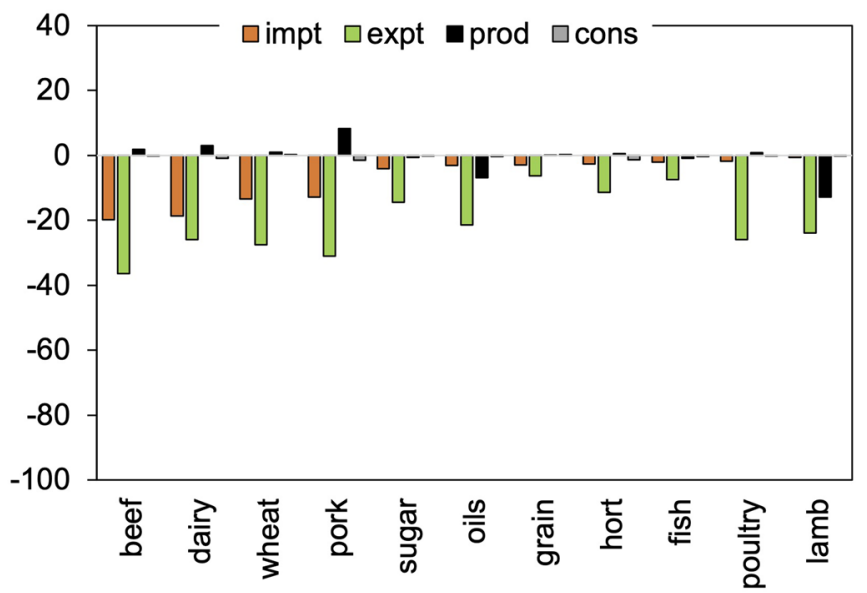

C

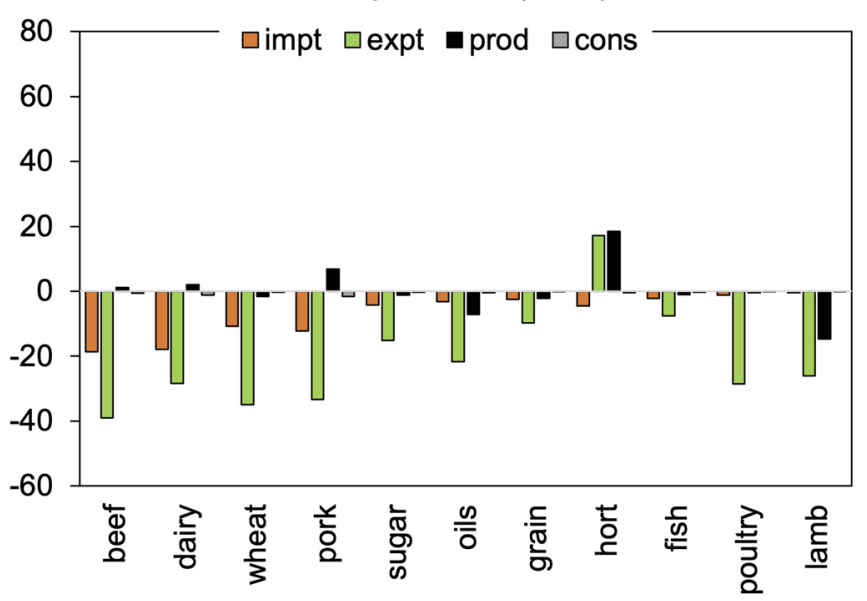

e

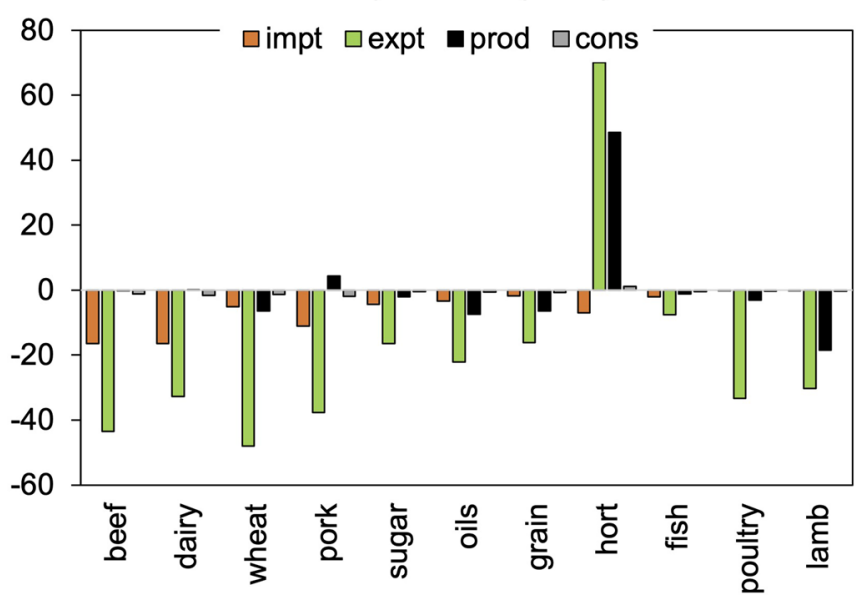

b

Hard Brexit

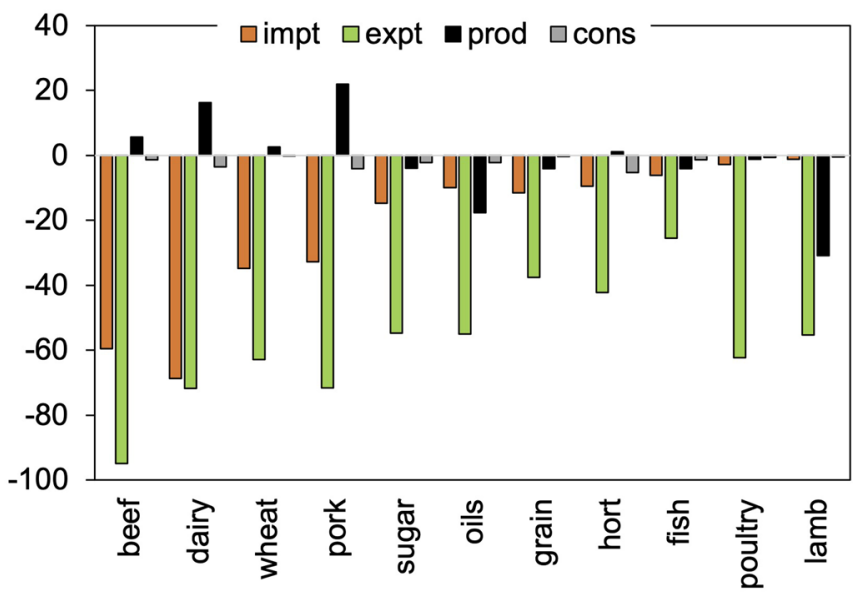

d

Subsidy reform $(50 \%)$

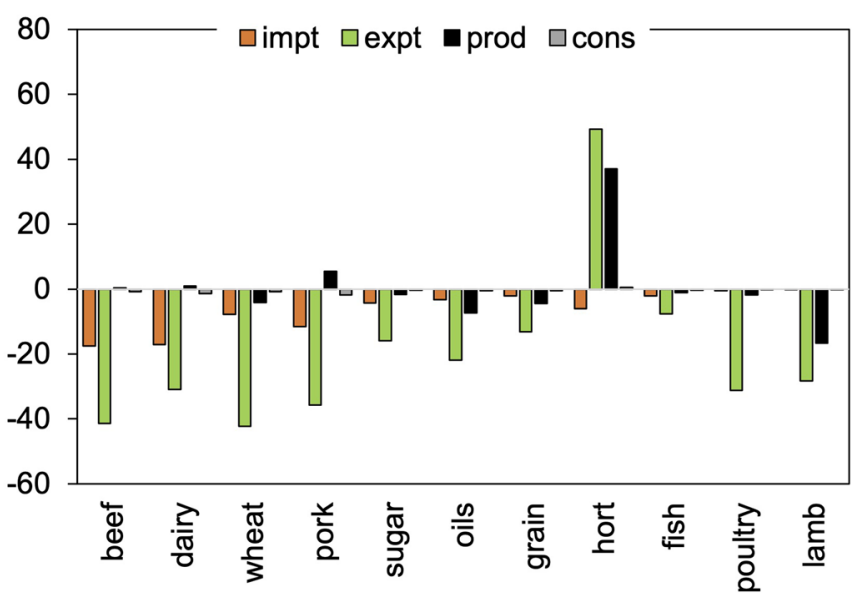

Extended Data Fig. 4 | Food-system changes for additional Brexit approaches. Food-system changes for combinations of Brexit approaches. Percentage changes in agricultural imports (impt), exports (expt), production (prod), and consumption (cons) for different combination of Brexit approaches, including different baselines (Soft Brexit without mutual tariffs vs Hard Brexit with mutual tariffs), and different levels of support for horticultural production ( $25 \%$ to $75 \%$ ) in agricultural subsidy reforms. 


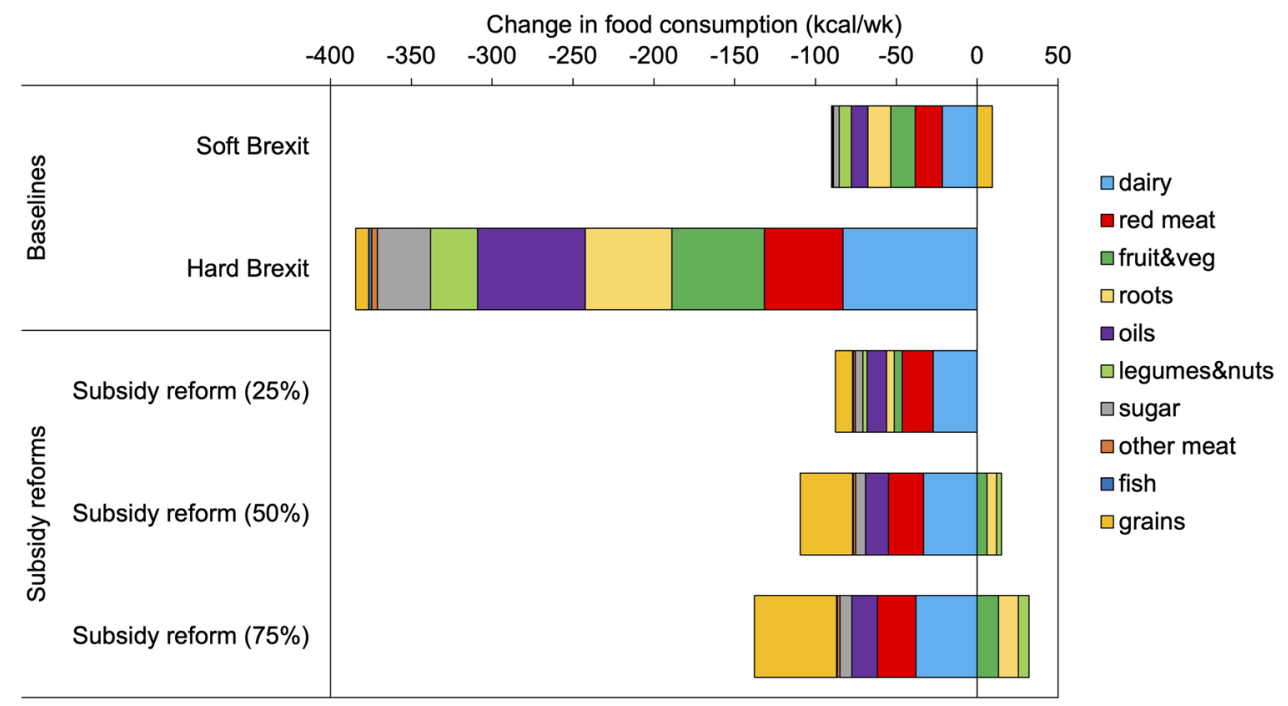

Extended Data Fig. 5 | Change in food consumption per person (kilocalories per week, kcal/wk) by food group for additional Brexit approaches. The approaches include two different baselines, a Soft Brexit without mutual tariffs vs Hard Brexit with mutual tariffs, and they include three scenarios of agricultural subsidy reform with different levels of support for horticultural production ( $25 \%$ to $75 \%$ ). 


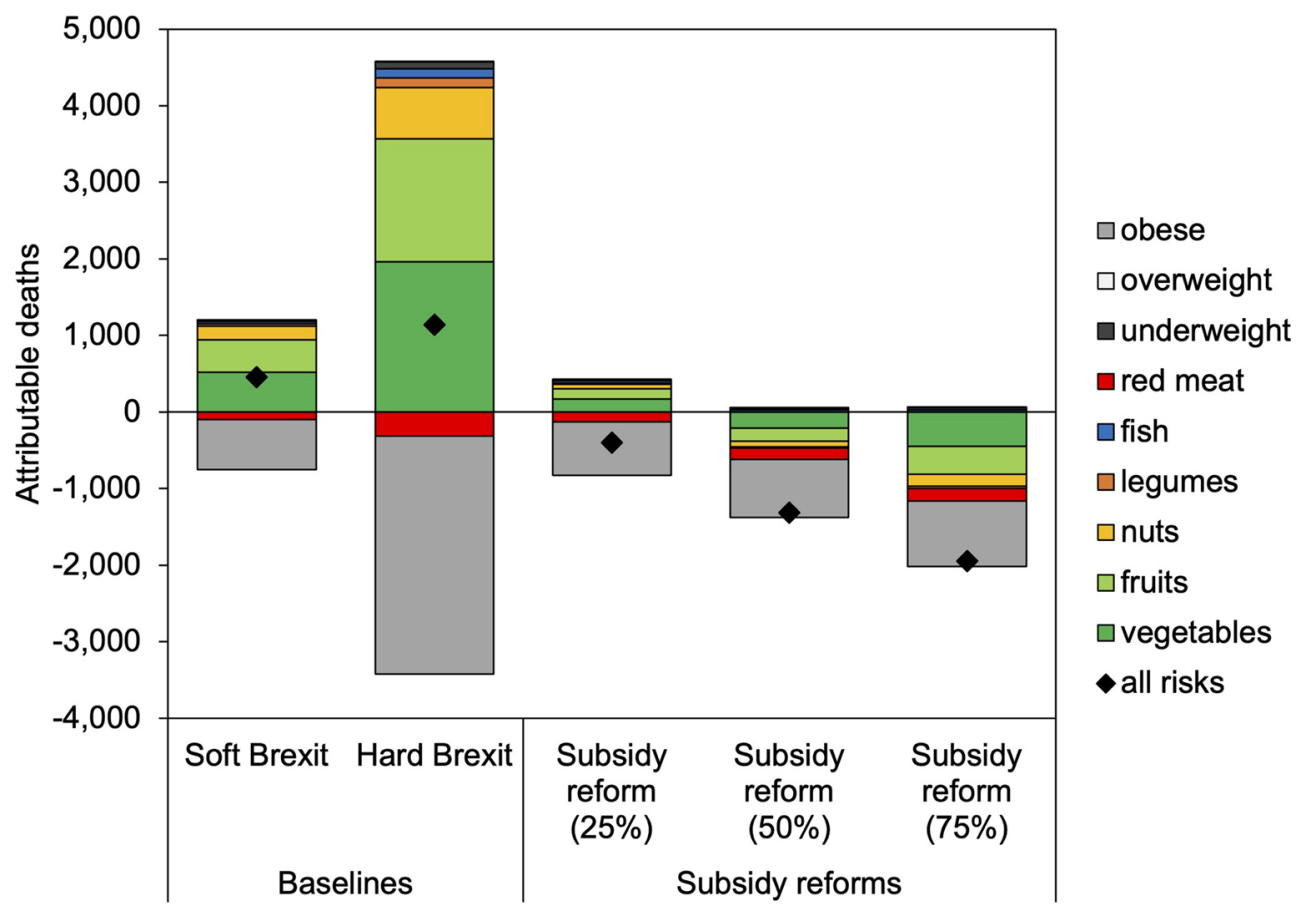

Extended Data Fig. 6 | Number of attributable deaths by risk factor for additional Brexit approaches. The approaches include two different baselines, a Soft Brexit without mutual tariffs vs Hard Brexit with mutual tariffs, and they include three scenarios of agricultural subsidy reform with different levels of support for horticultural production ( $25 \%$ to $75 \%$ ). 


\section{Reporting Summary}

Nature Research wishes to improve the reproducibility of the work that we publish. This form provides structure for consistency and transparency in reporting. For further information on Nature Research policies, see our Editorial Policies and the Editorial Policy Checklist.

\section{Statistics}

For all statistical analyses, confirm that the following items are present in the figure legend, table legend, main text, or Methods section.

n/a Confirmed

Х $\square$ The exact sample size $(n)$ for each experimental group/condition, given as a discrete number and unit of measurement

Х $\square$ A statement on whether measurements were taken from distinct samples or whether the same sample was measured repeatedly

$\triangle$ The statistical test(s) used AND whether they are one- or two-sided

Х $\square$ Only common tests should be described solely by name; describe more complex techniques in the Methods section.

Х $\square$ A description of all covariates tested

Х $\square$ A description of any assumptions or corrections, such as tests of normality and adjustment for multiple comparisons

$\checkmark$ A full description of the statistical parameters including central tendency (e.g. means) or other basic estimates (e.g. regression coefficient)

$\bigotimes$ AND variation (e.g. standard deviation) or associated estimates of uncertainty (e.g. confidence intervals)

$\bigotimes \square \begin{aligned} & \text { For null hypothesis testing, the test statistic (e.g. } F, t, r \text { ) with confidence intervals, effect sizes, degrees of freedom and } P \text { value noted } \\ & \text { Give } P \text { values as exact values whenever suitable. }\end{aligned}$

Х $\square$ For Bayesian analysis, information on the choice of priors and Markov chain Monte Carlo settings

Х $\square$ For hierarchical and complex designs, identification of the appropriate level for tests and full reporting of outcomes

Х $\square$ Estimates of effect sizes (e.g. Cohen's $d$, Pearson's $r$ ), indicating how they were calculated

Our web collection on statistics for biologists contains articles on many of the points above.

\section{Software and code}

Policy information about availability of computer code

Data collection Data used for the analysis include trade and tariff data from the Global Trade Analysis Project (GTAP), food availability and waste data from the Food and Agricultural Organization, and mortality and population data from the Global Burden of Disease project. The latter two are open source and the first one can be obtained by everybody for a fee.

Data analysis We used the MAGNET model (coded in GEMPACK) for the trade-related analysis, and we used a comparative risk assessment framework (coded in GAMS) for the health analysis. Both models are described in detail in the study and in previous papers (see Methods section for details).

For manuscripts utilizing custom algorithms or software that are central to the research but not yet described in published literature, software must be made available to editors and reviewers. We strongly encourage code deposition in a community repository (e.g. GitHub). See the Nature Research guidelines for submitting code \& software for further information.

\section{Data}

Policy information about availability of data

All manuscripts must include a data availability statement. This statement should provide the following information, where applicable:

- Accession codes, unique identifiers, or web links for publicly available datasets

- A list of figures that have associated raw data

- A description of any restrictions on data availability 


\section{Field-specific reporting}

Please select the one below that is the best fit for your research. If you are not sure, read the appropriate sections before making your selection.
Life sciences
Х Behavioural \& social sciences
Ecological, evolutionary \& environmental sciences

For a reference copy of the document with all sections, see nature.com/documents/nr-reporting-summary-flat.pdf

\section{Behavioural \& social sciences study design}

All studies must disclose on these points even when the disclosure is negative.

Study description

Research sample

Sampling strategy

Data collection

Timing

Data exclusions

Non-participation

Randomization

\section{Quantitative modelling study based on national-level trade, production, and consumption data}

N/A

N/A

N/A

N/A

N/A

N/A

N/A

\section{Reporting for specific materials, systems and methods}

We require information from authors about some types of materials, experimental systems and methods used in many studies. Here, indicate whether each material, system or method listed is relevant to your study. If you are not sure if a list item applies to your research, read the appropriate section before selecting a response.

\begin{tabular}{|c|c|}
\hline $\mathrm{n} / \mathrm{a}$ & Involved in the study \\
\hline Х & $\square$ Antibodies \\
\hline Х & $\square$ Eukaryotic cell lines \\
\hline 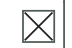 & $\square$ Palaeontology and archaeology \\
\hline$\bigotimes$ & $\square$ Animals and other organisms \\
\hline$\bigotimes$ & $\square$ Human research participants \\
\hline$\bigotimes$ & $\square$ Clinical data \\
\hline Х & $\square$ Dual use research of concern \\
\hline
\end{tabular}

Methods

$\mathrm{n} / \mathrm{a}$ Involved in the study

Х $\square$ ChIP-seq

Х Flow cytometry

$\bigotimes \square$ MRI-based neuroimaging 